\title{
The impact of RNA standardization and heterogeneous gene expression on the results of cDNA array of human breast carcinoma
}

\author{
REZA KHOSHNOUD ${ }^{1}$, QIMIN HE ${ }^{2,3}$, MARIA SYLVÁN ${ }^{4}$, AIDA KHOSHNOUD ${ }^{2}$, MADLEEN IVARSSON ${ }^{2}$, \\ TOMMY FORNANDER ${ }^{1}$, JONAS BERGH ${ }^{1}$, JAN FRISELL ${ }^{5}$, LARS-ERIK RUTQVIST ${ }^{2}$ and SVEN SKOG $^{2,3}$ \\ ${ }^{1}$ Department of Oncology, Karolinska University Hospital, Södersjukhus, Sjukhusbacken 10, S-118 83 \\ Stockholm; ${ }^{2}$ Department of Oncology Clinic Research Laboratory, Novum, KFC S-141 86 Stockholm, \\ Sweden; ${ }^{3}$ Sino-Swed Molecular Bio-Medical Research Institute, Shenzhen, P.R. China; ${ }^{4}$ Departments \\ of Pathology, and ${ }^{5}$ Surgery, Karolinska University Hospital, S-141 86 Stockholm, Sweden
}

Received October 6, 2009; Accepted November 19, 2009

DOI: 10.3892/ijmm_00000399

\begin{abstract}
DNA microarray is an established technique. However, difficulties such as handling tissue samples under RNase-free conditions, the heterogeneous tumor composition, i.e. non-malignant versus malignant cells and different pathologic types of malignant cells, and lack of appropriate reference may limit the potentially benefit of this method in clinical use. In this study, we examined how standardization of gene expression to total mg RNA or mg tissue and tumor heterogeneity affect the final results. We found that the gene expression of human breast tumors was $\sim 9$ times higher in malignant tissue as compared to the non-malignant tissue when expressed per total mg RNA, but 40 times higher when expressed per mg tissue. Genes that were expected to act as housekeeping genes (PUC18, RPL and B-actin) varied between different parts of the tumor and also between non-malignant and malignant tissues, excluding them as reference genes. We also found that the gene expression differed in various parts of the breast tumor, probably due to a mixture of different types of cells, i.e. non-malignant and malignant cells. To find out if the variations in the gene expression were due to cell heterogeneity we used microdissection to collect malignant cells separately. We found that the gene expression was markedly different in the isolated malignant cells as compared to the gene expression of the bulk tumor tissue. Thus, to be able to evaluate results from cDNA array gene expression experiments it is, to our opinion, necessary to work with pure tumor cell populations, until solid information is available on the impact of stromal component. Housekeeping genes should
\end{abstract}

Correspondence to: Dr Reza Khoshnoud, Department of Oncology, Karolinska University Hospital, Södersjukhuset, Sjukhusbacken 10, S-118 83 Stockholm, Sweden

E-mail: mahmoud.khoshnoud@karolinska.se

Key words: human breast carcinoma, cDNA array, mRNA, RNA, degradation of RNA be handling with care and mg tissue may be preferred instead of $\mu \mathrm{g}$ RNA for standardization.

\section{Introduction}

Breast cancer is a heterogenic disease, both histopathologically and clinically. Many potential prognostic and predictive factors of breast cancer have been suggested and some of them are used to estimate the level of risk and thereby suggesting adequate treatment. Useful risk factors are patient's age, tumor size, lymph node status, estrogen and progesterone status, Her-2 neu receptor positivity and proliferation rate.

Advances in molecular biological research have led to better understanding of tumor biology and to identification of prognostic and predictive biological factors and signatures. The use of cDNA microarrays for studying gene expression of cancer has increased during the last decade. Gene expression profiles may identify specific phenotypes (diagnosis), establish a patient's expected outcome (prognosis), and indicate the likelihood of a beneficial effect of a specific therapy (prediction) (1-3). cDNA microarray allows the comparison of gene expression profiles from two or more tissues or the same tissue in different biological states (4).

Molecular analysis of tumor requires methods that allow rapid and reproducible detection of alteration in gene expression. The question is how the quality of mRNA changes when using different treatment of tissues samples and isolation techniques. There are still few studies on preparation of RNA for cDNA microarray in malignant tissues. An optimized protocol regarding optimal tissue acquisition, processing, and analysis procedures for exploring the gene expression should be available when using this technology. cDNA microarrays are performed on chips, glass slides, or filters. There is no compelling evidence of major differences in the accuracy or reproducibility of the various microarray platforms (5-7). Only fresh or appropriately frozen tissues provide the necessary quality of RNA for microarray. However, one concern with frozen tissue banks is the frequent lack of a standardized approach for tissue acquisition and processing. Furthermore, 
oxygen deprivation occurring upon surgery can trigger a hypoxic response, characterized by an altered expression of specific genes (8-11). Several of these genes are transcription factors that further affect the expression of their target genes $(9,12)$. Thus, factors influencing the molecular quality of tissues are the type of specimen, pre-excision hypoxia, preservation treatment of the tissue, extraction method, type and length of storage and freeze and thaw. Acellular and pancellular tissues are also less labile than densely cellular tissue (13).

In this study, we investigated how tumor heterogeneity, RNA standardization and housekeeping genes affect the evaluation of gene expression determined by cDNA microarray. We also showed the possibility to overcome these problems by using microdissection by Laser Capture Microscope (LCM).

\section{Materials and methods}

Patients. Samples from breast tumors of six women who were referred at the Department of Endocrine Surgery, Karolinska University Hospital, Huddinge, were collected, and prepared for the cDNA array analysis as describe below. Routine breast surgery procedures were used, and to avoid RNA degradation, the tissues samples were put into RNAse free tubes containing RNA Later buffer (Qiagen GmbH, Germany) within 10-15 min after operation, analyzed directly for cDNA array or stored at $-70^{\circ} \mathrm{C}$. Specimens consisted of invasive ductal breast cancer (IDC) and ductal breast cancer in situ (DCIS). Normal breast tissues were obtained from three patients (no. 1,2 and 6) who underwent surgery for their breast cancer. The gene expression of tumor and normal tissues is based of patients no. 1,2 and 6 . The samples from the other patients could not be used for gene expression because of problem to fully evaluate the results. The samples supplied to this study were not tissues removed specially for research but were excess tissue not essential for routine diagnosis and histophatological staging. Patients were required to give consent.

Laser capture microscope. Individual normal (non-malignant) and malignant cells were collected from the tissue section of human breast carcinoma (patient no. 6) by Laser Capture Microscope (LCM) technique (Arcturus Ltd., UK). A skilled pathologist judged the type of cells, i.e. malignant versus non-malignant. The cells were collected into RNAse-free tubes and immediately prepared for RNA amplification and extraction according manufacturer's protocol (Arcturus Ltd.). The RNA extracts were stored at $-70^{\circ} \mathrm{C}$ before the cDNA array analysis.

RNA extraction. Total RNA was isolated using an RNA-Bee isolation kit (BioSite, Sweden). Samples of $50 \mathrm{mg}$ tissue were homogenized in $1 \mathrm{ml}$ RNA-Bee, initially using a pair of RNAfree scissors and then the samples were homogenized. Chloroform $(0.2 \mathrm{ml})$ was added to the homogenized sample. The sample was stored on ice for $5 \mathrm{~min}$ and then centrifuged at $12,000 \mathrm{x} \mathrm{g}$ for $15 \mathrm{~min}$. The colorless aqueous phase was collected and $0.5 \mathrm{ml}$ of isopropanol was added to the sample (aqueous phase) and then the sample was stored at room temperature for $10 \mathrm{~min}$ before it was centrifuged at $12,000 \mathrm{x} \mathrm{g}$ for $5 \mathrm{~min}$. The RNA pellet was washed twice with $75 \%$ ethanol and then the sample was dried for $10 \mathrm{~min}$. The total amount of RNA was measured at 260 and $280 \mathrm{~nm}$ in an UV spectrophotometer.

Quality of total RNA. The integrity of the total RNA was analyzed on a denatured $1 \%$ agarose/formaldehyde gel according to the manufacturer's standard protocol (Qiagen $\mathrm{GmbH})$.

cDNA array. Human Signal Transduction Pathway Finder Gene of 87 genes (the GEArray Q Series Human Signal Transduction Pathway Finder Gene Array: HS-008, Super Array Inc., Maryland, Bethesda, MD, USA), corresponding to 18 signal transduction pathways, was used for this experiment. PUC18 and RPL were used as negative controls and $\beta$-actin was used as positive control.

Total RNA (5 $\mu \mathrm{g})$ were used for each labelling. The total RNA was used as a template for the biotinylated probe synthesis. Probe preparation and hybridization of the membranes were done according to the manufacturer's manual as described by SuperArray Inc. The only modification of the protocol was a change of the washing temperature and time from $60^{\circ} \mathrm{C}$ for $15 \mathrm{~min}$ to $68^{\circ} \mathrm{C}$ for $20 \mathrm{~min}$ for washing solution no. 1 and 2. Quantitative data were obtained using AGFA Curix 60 photographic film (AGFA, Sweden). The results were obtained from two experiments (two determinations per each experiment). The deviation in the determination was $<10 \%$.

\section{Results}

Standardization of gene expression. In this part of the study, we examined how gene expression values may change when normalizing to total $\mathrm{mg}$ RNA or $\mathrm{mg}$ tissue. The $\mathrm{mg}$ tissue corresponds approximately to the number of cells in a tissue. In this study, we used malignant and the non-malignant tissues from the same patient. We found that the total RNA concentration in the malignant tissue was $\sim 12$ times higher (0.5 $\mu \mathrm{g} / \mathrm{mg}$ tissue) as compared to the non-malignant tissue (0.04 $\mu \mathrm{g} / \mathrm{mg}$ tissue) (Fig. 1A), which should be expected in tissues containing growing cells. The gene expression was generally higher in the malignant tissue as compared to the non-malignant tissue independent of normalizing to total RNA (Fig. 1B) or mg tissue (Fig. 1C). However, the gene expression was $\sim 9$ times higher in the malignant tissue as compared to the non-malignant tissue when normalizing to total RNA, but $\sim 40$ times higher when normalizing to $\mathrm{mg}$ tissue. Since the non-malignant cells are in $\mathrm{G}_{0}$ stage of the cell cycle, while the malignant cells are in $G_{1}, S-$ and $G_{2}$ stages, the non-malignant and the malignant cells are not comparable from growth related compounds point of view. Thus, it should be more accurate to normalize to number of cells than to total RNA, when comparing non-malignant tissue to malignant tissue. It is not possible to count cells in a tissue, therefore in this study we used mg tissue, which approximately corresponds to number of cells.

Gene expression in various part of the tumor. Herein we investigated the degree of variation in gene expression in 
A
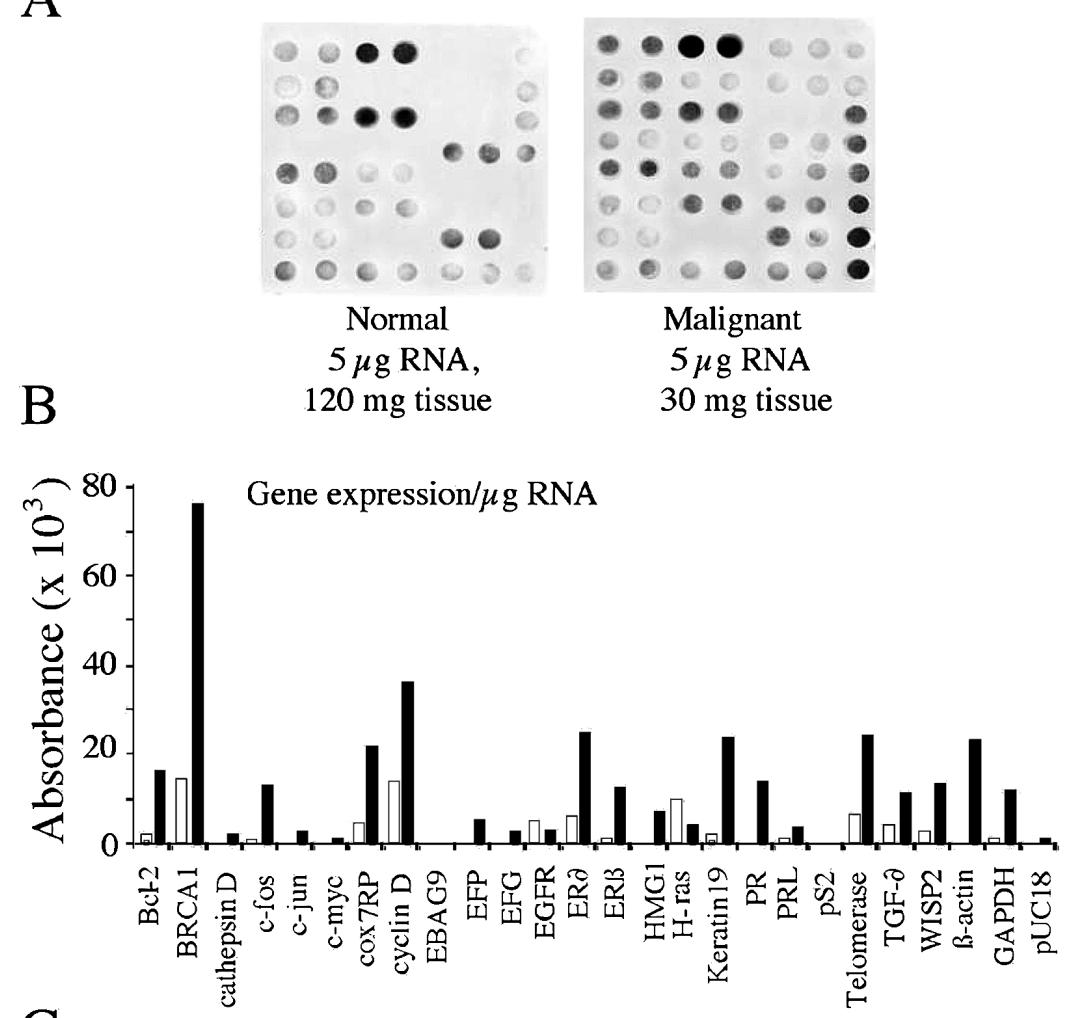

C

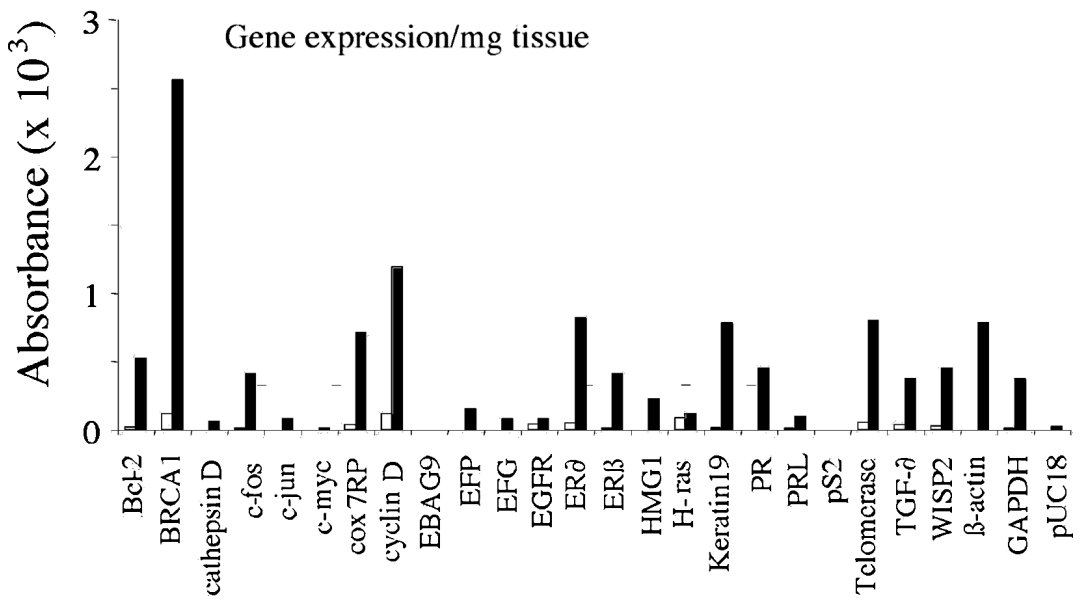

Figure 1. Gene expression by means of cDNA array of invasive ductual breast carcinoma of one patient (patient no. 1). (A) Example of cDNA array of normal non-malignant and malignant tissue of 23 genes and 3 housekeeping genes; (B and C) are results from part A expressed as per $\mu \mathrm{g}$ RNA (B) and per mg tissue (C). ( $\square$ ) normal tissue; (ロ) malignant tissue.

different parts of the human breast tumor. We cut the breast tumor (invasive ductal breast cancer, patient no. 2) in 5 pieces and measured the gene expression in each of them by means of cDNA-array. Total RNA $(<0.5 \mu \mathrm{g})$ was enough for the cDNA array analysis, corresponding to a fine needle biopsy. The gene expression between the various pieces differed 2-4 times (Fig. 2). We also found that the expression of housekeeping genes deviated markedly between malignant and non-malignant tissues, and thus were not useful as reference genes (Fig. 2).

Microdissection. To overcome the contribution of nonmalignant cells to the gene expression of the malignant cells we used microdissection by means of a Laser Capture Microscope. Thirty malignant individual cells were collected from a section of the breast tumor (patient no. 6) by a pathologist; the RNA was extracted and then amplified by means of an amplification kit provided by the company (Arcturus Ltd.). The gene expression was determined by cDNA array. In parallel we cut a piece of the same tumor ( $\sim 5 \mathrm{~mm}$ in diameter), extracted the RNA and then determined the gene expression in the same manner as for the single malignant cells. Of the genes we detected, there was an extensive difference in the expression between individual malignant cells and the expression seen in the piece of the tumor tissue. The results are shown in the Fig. 3. 


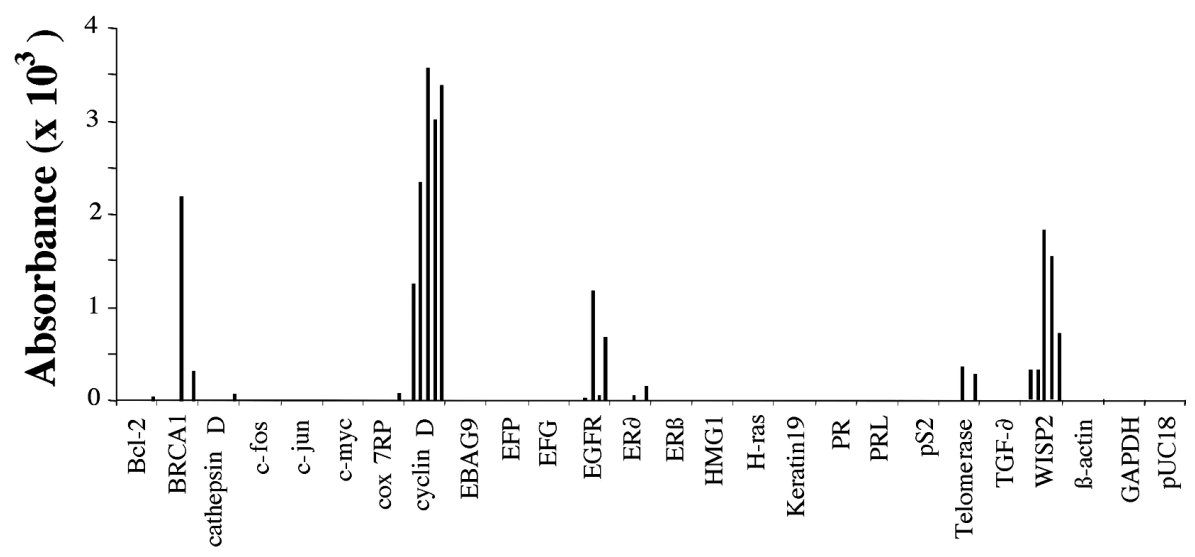

Figure 2. Gene expression of invasive ductual breast carcinoma of one patient (patient no. 2). The tumor was cut into five pieces and the gene expression was determined by means of cDNA array. Each bar represents one piece of the tumor.

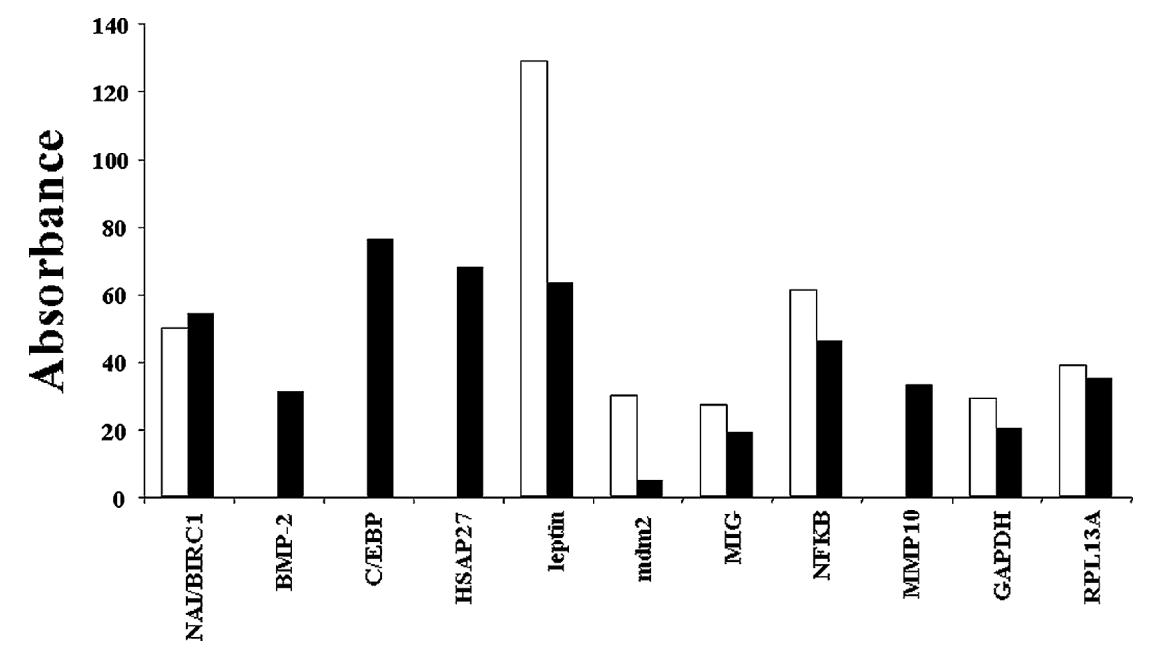

Figure 3. Gene expression of invasive ductual breast carcinoma of one patient (patient no. 6). A smear of part of the tumor was applied to glass and fixed. By means of a microdissection (see Materials and methods), single malignant cells were isolated, RNA extracted and genes expressions was determined by cDNA array $(\square)$. Gene expression of a piece of the tumor, including both non-malignant and malignant cells, was also determined by means of cDNA array ( $\mathbf{\square})$.

\section{Discussion}

The study of human cancer has mainly been limited to surgical and histophatological description of the malignancy up to almost a decade ago. After completion of the Human Genome Project attention has been turned to functional genomics and proteomics, and thus increasing number of studies have been done on human malignant tissues using cDNA array, for example leukemia, lymphoma, adenocarcinoma of lung, breast, melanoma, and prostate. Despite the concern about the mRNA integrity, due to inaccurate sampling procedures, the gene expression based on cDNA array seems to have diagnostic, prognostic and predictive values, as well as being able to modify the way that tumors are treated. However, recent studies show that a number of factors during the cDNA array procedure can affect the final results of gene expression. For example, the way tumor tissues are collected and preserved influence the mRNA integrity, use of inaccurate 'housekeeping genes' and tumor heterogeneity affects the gene expression levels estimated (14). Such uncertainty in the cDNA methods may explains the lack of compliance between some clinical studies.

Gene expression of cells is determined by measuring the mRNA concentration. cDNA microarray measures the steady-state levels of mRNA. Different genes are expressed in various degrees in different tumors, and in the same tumor at different times. Also, the concentration of mRNA measured depends on where, when and how the samples have been collected. The development of invasive tumors is a dynamic process including several different stages also involving activation and deactivation of different genes. Furthermore, a growing tumor demands more oxygen and nutrition which could result in an uneven tumor content regarding malignant and normal cells, probably also appearance of necrosis in the centre of the tumor with well feed cells at the tumor margin.

Zhu at al showed in a study on breast ductal carcinoma in situ and on invasive carcinoma that gene expression profiles obtained from cells collected from different location in the same tumor were different (15). A malign tumor that develops 
in a particular organ has its own composition. The host organ may or may not have a homogeneous structure, for instance lung and liver are homogeneous while breast is a heterogeneous organ. Thus, in the case of breast carcinoma the content of a sample can vary depending on the characteristics of the tumor (ducal or lobular) and patient (age, prepostmenopausal, parity status).

In this study, we found that normalization of gene expression per $\mathrm{mg}$ tissue gave larger differences between non-malignant and malignant tissues, than normalization to $\mu \mathrm{g}$ total RNA. The amount of RNA was low in non-growing cells, but increased when the cells became proliferating. Since the non-malignant tissue represents almost non-growing cells, while malignant tissues proliferate, from gene expression point of view they are not exactly comparable.

We also studied the variation in gene expression within the same tumor, and differences in gene expression profile between normal breast tissue and breast malignancy. We found a different expression profile between normal breast tissue and breast malignancy, which should be expected, but also within the same tumor. As expected in growing cells, our results showed higher levels of cell cycle related genes in the breast malignant cells. Very high level of cyclin D has been reported in human breast tumor cells. In MCF-7 Tam-resistant cells of breast origin, of 127 genes studied, only cyclin D1 was found to be overexpressed (16). We also found in this study that Bcl-2 and BRAC1 were overexpressed in the breast tumor as compared to normal breast tissue. Bcl-2 is supposed to inhibit apoptosis, and thus higher level of Bcl-2 expression may be promoting tumor growth (17-19). In contrast to our result, other groups have reported low level of BRCA1 in invasive breast cancer $(20,21)$. Similarly BRCA1 is upregulated in proliferating cells and high level of BRCA1 mRNA has been reported in growing cells $(22,23)$. Thus, caution must be used in interpreting studies in which this gene is overexpressed (20).

Our results showed that gene expression is not homogeneous in breast ductal carcinoma cells as well as in normal breast tissue. This heterogeneity in expression cannot be explained by the way we have processed the RNA, because we followed a standard procedure for all samples. However, it is possible that pre- and peri-operative conditions such as hypoxia influence the level of mRNA. This heterogeneous gene expression is in accordance with the histopathological heterogeneity found in breast cancer tumors.

In this study, we found that the reference genes we used were expressed at different levels in normal and breast malignant tissues. This is in accordance with earlier results, where 'Housekeeping' genes were expressed at different levels in normal and tumor cells (24). Several studies have demonstrated that the gene expression profiles of many commonly used internal controls may vary depending of tissue type, experimental conditions or pathological state (25-27). Lee and coworker analyzed a group of large mammalian microarray datasets including the NCI60 cancer cell line panel, a leukemia tumor panel, and a phorbol ester induction time course as well as human and mouse tissue panels. They found that 12 housekeeping genes commonly used showed considerable variability of expression both within and across microarray datasets (28). Such variability in gene expression of controls genes makes it difficult when evaluating tumor gene expression in relation to normal cells and can lead to incorrect conclusions. One method is to determine gene expression in individual tumor cells and normal cells by using the Laser Capture Microscope technique. This technique makes it possible to collect determinable numbers of welldefined cells and its combination with methods such as realtime quantitative RT-PCR will allow a more precise determination of cell specific gene expression (29-31). However, it has been reported that LCM technique may induce degradation of RNA during the procedure of laser capture microdissection (32), making the conclusion less reliable. Despite this, the feasibility of combination of LCM and cDNA microarray hybridization has been demonstrated by Luo et al, who showed reproducible differences in gene expression between large and small neurons isolated from rat dorsal root ganglia (33).

A similar approach combining LCM, cDNA arrays and real-time quantitative PCR, was used showing altered gene expression patterns at various stages of breast cancer progression (31). Comparing gene expression profiles of carcinoma cells obtained using macrodissection or microdissection, led to the conclusion that stroma cells disturb tumor gene expression profiles (34). However, De Bruin et al found in rectal carcinoma a minor influence of stroma cells on tumor cell gene expression profiles and concluded that macrodissection can be adequately used to obtain reliable data (35).

Yang et al showed different gene expression profiles in node-negative breast tumor cells, in which 17 patients with ER- $\alpha$ positive tumor were compared with 11 patients who had ER- $\alpha$ negative tumors. Gene expression profiles were analyzed in both bulk tumors and laser capture microdissection (36). In another study by Makino et al on carcinoma of gastric and on colon using PCR after collecting cells by LCM, different gene expression profiles were found in the malignant cells as compared to the stroma cells (37). By using LCM technique in combination with complementary cDNA microarrays, Nakamura and coworker found a novel panel of candidate marker genes for pancreatic cancer, due to the high purity of the cells obtained by LCM (38). Furthermore, in many other studies on different types of malignancies such as ovarian $(39,40)$, breast $(31)$, prostate $(41)$, gastric (42), pancreas (38), lung adenocarcinoma (43) and non-small cell lung cancer (44) combination of LCM and cDNA microarray, resulted in the discovery of new cancer markers.

The amount of tissues we used in this study for cDNA array analysis corresponded to the amount of tumor material obtained with fine needle biopsy (FNAB). This amount of tissues is enough for cDNA array analysis. FNAB and/or core needle biopsy (CBX) have been used to collect samples from primary and metastatic tumors for many decades. FNAB is safe, simple, and inexpensive and already commonly used with routine investigation of tumors. Cancer cells have poor attachment and it is more probable to be grabbed by fine needle aspiration then normal cells. It could also be used together with sonography or X-ray to reach tumor sites deep in the body. mRNA yield by the mean of fine needle biopsy is enough to perform microarray analyses and obtain gene expression profiles. 
Furthermore, it is possible to take more than one FNAB from the tumor and thus get an average of the gene expression in the tumor. Symmans et al found in 68 patients with breast cancer that both FNAB and CBX yield a similar quality and quantity of total RNA and were suitable for cDNA microarray analyses in 70-75\% of single-pass samples (45). Furthermore, Sotiriou et al reported on the suitability of FNAB-derived cDNA microarray in breast cancer (46). However, in another study, $<15 \%$ of FNABs were reported to be sufficient for microarray analyses (47). Though, inconsistent results in relation to suitability of FNAB are reported. The present study showed gene expression analyses by cDNA array technology is applicable to samples from FNAB.

We conclude that gene expression study of breast carcinoma using cDNA microarray should be done with caution because of tumor heterogeneity. It is also important to consider appropriate housekeeping genes and standardization of mRNA. We must stress that this study was based on few tumor samples and that the conclusion, which can be made are limited.

\section{Acknowledgements}

This study was performed on grants from Karolinska Institute, Stockholm Läns landsting, and core facilities from Research Centre, Novum, Karolinska University Hospital, Huddinge.

\section{References}

1. Hayes DF, Bast RC, Desch CE, et al: Tumor marker utility grading system: a framework to evaluate clinical utility of tumor markers. J Natl Cancer Inst 88: 1456-1466, 1996.

2. Pawitan Y, Bjohle J, Amler L, et al: Gene expression profiling spares early breast cancer patients from adjuvant therapy: derived and validated in two population-based cohorts. Breast Cancer Res 7: R953-R964, 2005.

3. Hayes DF, Trock B and Harris AL: Assessing the clinical impact of prognostic factors: when is 'statistically significant' clinically useful? Breast Cancer Res Treat 52: 305-319, 1998.

4. Marx J: DNA arrays reveal cancer in its many forms. Science 289: 1670-1672, 2000.

5. Richmond CS, Glasner JD, Mau R, Jin H and Blattner FR: Genome-wide expression profiling in Escherichia coli K-12. Nucleic Acids Res 27: 3821-3835, 1999.

6. Carulli JP, Artinger M, Swain PM, et al: High throughput analysis of differential gene expression. J Cell Biochem 30-31: S286-S296, 1998.

7. Cox JM: Applications of nylon membrane arrays to gene expression analysis. J Immunol Methods 250: 3-13, 2001.

8. Wang GL and Semenza GL: General involvement of hypoxiainducible factor 1 in transcriptional response to hypoxia. Proc Natl Acad Sci USA 90: 4304-4308, 1993.

9. Wenger RH, Rolfs A, Marti HH, Bauer C and Gassmann M: Hypoxia, a novel inducer of acute phase gene expression in a human hepatoma cell line. J Biol Chem 270: 27865-27870, 1995.

10. Helfman T and Falanga V: Gene expression in low oxygen tension. Am J Med Sci 306: 37-41, 1993.

11. Fandrey J: Hypoxia-inducible gene expression. Respir Physiol 101: 1-10, 1995.

12. Goldberg MA and Schneider TJ: Similarities between the oxygensensing mechanisms regulating the expression of vascular endothelial growth factor and erythropoietin. J Biol Chem 269: 4355-4359, 1994.

13. Marchuk L, Sciore P, Reno C, Frank CB and Hart DA: Postmortem stability of total RNA isolated from rabbit ligament, tendon and cartilage. Biochim Biophys Acta 1379: 171-177, 1998.

14. Von Euler H, Khoshnoud R, He Q, et al: Time-dependent RNA degradation affecting cDNA array quality in spontaneous canine tumours sampled using standard surgical procedures. Int J Mol Med 16: 979-985, 2005.
15. Zhu G, Reynolds L, Crnogorac-Jurcevic T, et al: Combination of microdissection and microarray analysis to identify gene expression changes between differentially located tumour cells in breast cancer. Oncogene 22: 3742-3748, 2003.

16. Skog S, He Q, Khoshnoud R, Fornander T and Rutqvist LE: Genes related to growth regulation, DNA repair and apoptosis in an oestrogen receptor-negative (MDA-231) versus an oestrogen receptor-positive (MCF-7) breast tumour cell line. Tumour Biol 25: 41-47, 2004.

17. Pietenpol JA, Papadopoulos N, Markowitz S, Willson JK, Kinzler KW and Vogelstein B: Paradoxical inhibition of solid tumor cell growth by bcl2. Cancer Res 54: 3714-3717, 1994.

18. McDonnell TJ and Korsmeyer SJ: Progression from lymphoid hyperplasia to high-grade malignant lymphoma in mice transgenic for the $\mathrm{t}(14 ; 18)$. Nature 349: 254-256, 1991.

19. McDonnell TJ, Troncoso P, Brisbay SM, et al: Expression of the protooncogene bcl-2 in the prostate and its association with emergence of androgen-independent prostate cancer. Cancer Res 52: 6940-6944, 1992.

20. Chodosh LA: Expression of BRCA1 and BRCA2 in normal and neoplastic cells. J Mammary Gland Biol Neoplasia 3: 389-402, 1998.

21. Thompson ME, Jensen RA, Obermiller PS, Page DL and Holt JT: Decreased expression of BRCA1 accelerates growth and is often present during sporadic breast cancer progression. Nat Genet 9: 444-450, 1995.

22. Gudas JM, Li T, Nguyen H, Jensen D, Rauscher FJ III and Cowan KH: Cell cycle regulation of BRCA1 messenger RNA in human breast epithelial cells. Cell Growth Differ 7: 717-723, 1996.

23. Vaughn JP, Davis PL, Jarboe MD, et al: BRCA1 expression is induced before DNA synthesis in both normal and tumor-derived breast cells. Cell Growth Differ 7: 711-715, 1996.

24. Giricz O, Lauer-Fields JL and Fields GB: The normalization of gene expression data in melanoma: investigating the use of glyceraldehyde 3-phosphate dehydrogenase and $18 \mathrm{~S}$ ribosomal RNA as internal reference genes for quantitative real-time PCR. Anal Biochem 380: 137-139, 2008.

25. Bereta J and Bereta M: Stimulation of glyceraldehyde-3phosphate dehydrogenase mRNA levels by endogenous nitric oxide in cytokine-activated endothelium. Biochem Biophys Res Commun 217: 363-369, 1995.

26. Gibbs PJ, Cameron C, Tan LC, Sadek SA and Howell WM: House keeping genes and gene expression analysis in transplant recipients: a note of caution. Transpl Immunol 12: 89-97, 2003.

27. Hamalainen HK, Tubman JC, Vikman S, et al: Identification and validation of endogenous reference genes for expression profiling of $\mathrm{T}$ helper cell differentiation by quantitative realtime RT-PCR. Anal Biochem 299: 63-70, 2001.

28. Lee PD, Sladek R, Greenwood CM and Hudson TJ: Control genes and variability: absence of ubiquitous reference transcripts in diverse mammalian expression studies. Genome Res 12: 292-297, 2002.

29. Fink L, Seeger W, Ermert L, et al: Real-time quantitative RT-PCR after laser-assisted cell picking. Nat Med 4: 1329-1333, 1998.

30. Goldsworthy SM, Stockton PS, Trempus CS, Foley JF and Maronpot RR: Effects of fixation on RNA extraction and amplification from laser capture microdissected tissue. Mol Carcinog 25: 86-91, 1999.

31. Sgroi DC, Teng S, Robinson G, LeVangie R, Hudson JR Jr and Elkahloun AG: In vivo gene expression profile analysis of human breast cancer progression. Cancer Res 59: 5656-5661, 1999.

32. Michel C, Desdouets C, Sacre-Salem B, Gautier JC, Roberts R and Boitier E: Liver gene expression profiles of rats treated with clofibric acid: comparison of whole liver and laser capture microdissected liver. Am J Pathol 163: 2191-2199, 2003.

33. Luo L, Salunga RC, Guo H, et al: Gene expression profiles of laser-captured adjacent neuronal subtypes. Nat Med 5: 117-122, 1999.

34. Sugiyama Y, Sugiyama K, Hirai Y, Akiyama F and Hasumi K: Microdissection is essential for gene expression profiling of clinically resected cancer tissues. Am J Clin Pathol 117: 109-116, 2002.

35. de Bruin EC, van de Pas S, Lips EH, et al: Macrodissection versus microdissection of rectal carcinoma: minor influence of stroma cells to tumor cell gene expression profiles. BMC Genomics 6: 142, 2005.

36. Yang F, Foekens JA, Yu J, et al: Laser microdissection and microarray analysis of breast tumors reveal ER-alpha related genes and pathways. Oncogene 25: 1413-1419, 2006. 
37. Makino H, Uetake H, Danenberg K, Danenberg PV and Sugihara K: Efficacy of laser capture microdissection plus RTPCR technique in analyzing gene expression levels in human gastric cancer and colon cancer. BMC Cancer 8: 210, 2008.

38. Nakamura T, Furukawa Y, Nakagawa $\mathrm{H}$, et al: Genome-wide cDNA microarray analysis of gene expression profiles in pancreatic cancers using populations of tumor cells and normal ductal epithelial cells selected for purity by laser microdissection. Oncogene 23: 2385-2400, 2004.

39. Adib TR, Henderson S, Perrett C, et al: Predicting biomarkers for ovarian cancer using gene-expression microarrays. Br J Cancer 90: 686-692, 2004.

40. Ono K, Tanaka T, Tsunoda T, et al: Identification by cDNA microarray of genes involved in ovarian carcinogenesis. Cancer Res 60: 5007-5011,2000.

41. Huang JM, Lin TY, Chang D, Lin SL and Ying SY: Truncated Bcl-2, a potential pre-metastatic marker in prostate cancer. Biochem Biophys Res Commun 306: 912-917, 2003.

42. Katoh M: CLDN23 gene, frequently down-regulated in intestinaltype gastric cancer, is a novel member of CLAUDIN gene family. Int J Mol Med 11: 683-689, 2003.
43. Kobayashi K, Nishioka M, Kohno T, et al: Identification of genes whose expression is upregulated in lung adenocarcinoma cells in comparison with type II alveolar cells and bronchiolar epithelial cells in vivo. Oncogene 23: 3089-3096, 2004.

44. Kikuchi T, Daigo Y, Katagiri T, et al: Expression profiles of non-small cell lung cancers on cDNA microarrays: identification of genes for prediction of lymph-node metastasis and sensitivity to anti-cancer drugs. Oncogene 22: 2192-2205, 2003.

45. Symmans WF, Ayers M, Clark EA, et al: Total RNA yield and microarray gene expression profiles from fine-needle aspiration biopsy and core-needle biopsy samples of breast carcinoma. Cancer 97: 2960-2971, 2003.

46. Sotiriou C, Powles TJ, Dowsett M, et al: Gene expression profiles derived from fine needle aspiration correlate with response to systemic chemotherapy in breast cancer. Breast Cancer Res 4: R3, 2002.

47. Assersohn L, Gangi L, Zhao Y, et al: The feasibility of using fine needle aspiration from primary breast cancers for $\mathrm{cDNA}$ microarray analyses. Clin Cancer Res 8: 794-801, 2002. 